\title{
The value of synovial fluid analysis in the assessment of knee joint destruction in arthritis in a three year follow up study
}

\author{
S Åman, J Risteli, R Luukkainen, L Risteli, M Kauppi, P Nieminen, M Hakala
}

\begin{abstract}
Objectives-To assess the predictive significance of synovial fluid (SF) analysis for progressive radiological knee joint destruction in arthritis.

Methods-Altogether 55 patients with arthritis and knee joint effusion were included in the study. The diagnosis was rheumatoid arthritis (RA) for 44 of them, chronic seronegative spondylarthropathy for seven and juvenile rheumatoid arthritis for four. The mean age of the patients was 51.8 (SD 14.9, range 19-82) years, and the mean duration of disease 10.9 (SD 9.2, range 0.5-37) years. In addition to the routine laboratory tests, different markers of collagen synthesis and breakdown in serum and SF were assessed. The radiological grade of the knee joint was assessed by Larsen's method at the baseline and after a three year follow up.
\end{abstract}

Results-During the follow up, Larsen's grade deteriorated in $22(40 \%)$ patients. These patients had a significantly higher median level of cross linked carboxyterminal telopeptide of type I collagen (ICTP) in SF at entry than those who had a stable index $(p=0.035)$. Serum ICTP did not have any predictive value for a specific joint. The median levels of total SF leucocytes $(p=0.012)$ and the subgroup of polymorphonuclear leucocytes $(p=0.018)$ were higher in the patients with a stable Larsen's index. However, the relation of SF leucocyte level to radiological progression could not be confirmed in the RA group.

Conclusion-It is concluded that SF analysis may help in the identification of patients with inflammatory arthritis who are at risk for progressive destruction in a particular joint. A high total SF leucocyte level is not necessarily associated with a poor prognosis. Instead, a high SF ICTP level seems to reflect accelerated bone degradation.

(Ann Rheum Dis 1999;58:559-562)

There is increasing evidence to suggest that synovial fluid (SF) analysis may help in analysing the further destruction of an individual joint in patients with arthritis. ${ }^{1-4}$ Much interest has been shown in the measurement of the synthesis and breakdown of different components of bone and cartilage. ${ }^{1-5}$ Saxne et al studied a group of patients with rheumatoid arthritis (RA) from whom knee joint SF had been aspirated 10 years previously and found a correlation between the SF proteoglycan concentrations and the degree of subsequent radiographic joint destruction. ${ }^{6}$ In two other studies, an increasing SF bone sialoprotein (BSP) concentration was accompanied by increasing degrees of knee joint damage. ${ }^{78} \mathrm{BSP}$ is a bone specific macromolecule that constitutes some $12 \%$ of the non-collagenous proteins in bone, being hence a major component of this group of proteins. $^{9}$ In a longitudinal study by Månsson et al, the concentrations of $\mathrm{SF}$ aggrecan-that is, the cartilage oligomeric matrix protein (a non-collagenous matrix protein) -were initially highest in the group of RA patients with developing joint destruction. ${ }^{8}$

We have earlier measured the breakdown of type I collagen using an assay of cross linked carboxyterminal telopeptide (ICTP) ${ }^{10}$ in the SF of 59 unselected patients with RA and hydropsy in a knee joint. SF ICTP was clearly related to the radiographic findings in the corresponding knee joint, as the patients with gross bone deformation had the highest SF ICTP concentrations. In addition, the markers for type I and type III collagen synthesis, the aminoterminal propeptides of type I (PINP) ${ }^{11}$ and type III procollagen (PIIINP), ${ }^{12}$ when measured from SF, correlated clearly with each other and with SF ICTP. ${ }^{13}$ In the present series, we looked for a connection between SF analysis at the baseline and radiological status after a three year follow up in 55 patients with arthritis.

\section{Methods}

PATIENTS

Altogether 55 patients with arthritis and knee joint effusion in the outpatient or inpatient departments of three rheumatism hospitals in Finland were included in the study. The diagnosis was $\mathrm{RA}^{14}$ for 44 of them, chronic seronegative spondylarthropathy for seven and juvenile rheumatoid arthritis for four. No patients with primary osteoarthritis were included. The patients with RA represented a subcohort of the 59 patients reported earlier. ${ }^{13}$ The patients with a baseline Larsen's grade of 5 for the knee joint were excluded from the study. The mean age of the patients was 51.8 (SD 14.9, range 19-82) years and the mean duration of the disease 10.9 (SD 9.2, range 0.5-37) years. The mean follow up time was 38.4 (SD 3.8, range 28-49) months. Fifty one patients had initially been treated with an intra-articular corticosteroid injection (triamcinolonhexacetonide $20 \mathrm{mg}$ ) and four with 
Table 1 Distribution of the Larsen's grades of knee joints at entry and at the three year visit

\begin{tabular}{lll}
\hline Larsen's grade & Baseline $n(\%)$ & Three years $n$ (\%) \\
\hline 0 & $12(21.8)$ & $7(12.7)$ \\
1 & $15(27.3)$ & $16(29.1)$ \\
2 & $14(25.5)$ & $11(20.0)$ \\
3 & $11(20.0)$ & $13(23.6)$ \\
4 & $3(5.5)$ & $7(12.7)$ \\
5 & $0(0)$ & $1(1.8)$ \\
Total & $55(100)$ & $55(100)$ \\
\hline
\end{tabular}

osmium acid. The mean cumulative duration of disease modifying antirheumatic drug (DMARD) and corticosteroid treatment was 91.8 (SD 18.0) \% and 50.9 (SD 46.0) \% of the follow up time, respectively. Three patients underwent total knee joint replacement surgery during the follow up.

CLINICAL, LABORATORY AND RADIOGRAPHIC EXAMINATIONS

Routine laboratory tests for the assessment of disease activity were performed. All SF aspirations were done for therapeutic reasons. The SF specimens were collected into sterile tubes and stored at $-20^{\circ} \mathrm{C}$, together with serum samples obtained at the same time. SF leucocyte counts were done before freezing.

The radiological state of the knee joint both at entry and at the three year follow up visit was assessed by one of the authors (RL), using Larsen's method ${ }^{15}$ to compare posteroanterior radiographs with a standard series. Larsen index scores are: grade $0=$ normal; $1=$ slight abnormality with one or more minor lesions (periarticular soft tissue swelling, periarticular osteoporosis, and slight joint space narrowing); $2=$ definite early abnormality with erosion (not obligatory) and joint space narrowing; $3=$ medium destructive abnormality (erosion obligatory); 4 = severe destructive abnormality (bone deformation present); and grade $5=$ mutilating abnormality (gross bone deformation). For this study, total joint replacement surgery of the knee was considered as Larsen's grade 5 .

\section{MARKERS OF COLLAGEN METABOLISM}

ICTP, PINP, and PIIINP were measured, respectively, in duplicate 100,50 , and $200 \mu \mathrm{l}$ aliquots of serum, of undiluted SF in the case of ICTP, and of appropriately diluted (using assay buffer) SF in the case of the procollagen propeptides. Equilibrium radioimmunoassays for the human antigens were used ${ }^{10-12}$ with reagents supplied by Orion Diagnostica (FIN90460 Oulunsalo, Finland). The intra-assay and interassay coefficients of variation of the three markers tested with human serum samples are less than $10 \% .^{10-12}$ An aliquot of each serum sample was centrifuged within one hour after aspiration at $1800 \mathrm{~g}$ for two periods of 20 minutes. Intra-assay variation of the SF samples was $4.4 \%$ for PINP and $5.7 \%$ for PIIINP. The SF samples of the series were not centrifuged. We later tested the effect of centrifugation on the results in five additional patients. Centrifugation was found to decrease the levels of the markers of collagen metabolism in SF to the same extent as does centrifugation of plasma into serum. With the exception of one sample each, the level of the markers after centrifugation was lower compared with native samples by amounts varying from 6.3 to $11.7 \%$ for SF ICTP and from 0.2 to $1.4 \%$ for SF PIIINP.

\section{STATISTICAL ANALYSIS}

The data were analysed on a personal computer using SOLO statistical software. ${ }^{16}{ }^{17}$ MannWhitney test, Kruskal-Wallis test and $\chi^{2}$ statistics were used as appropriate.

\section{Results}

At entry, SF ICTP correlated positively with Larsen's index. Table 1 shows the distribution of Larsen's grades at entry and at the three year visit. The median SF ICTP concentrations in the baseline Larsen's grade groups $0-4$ were $10.8,15.5,12.5,18.3$ and $33.8 \mu \mathrm{g} / 1$, respectively $(\mathrm{p}=0.009)$. The radiological index deteriorated in $22(40 \%)$ patients, but remained stable in 33 patients $(60 \%)$. Table 2 shows the median baseline values of different markers in both groups. The median SF ICTP concentration was higher in the patients with a deteriorating Larsen's grade than in those with a stable one $(p=0.035)$. When tested only in the patients with RA $(\mathrm{n}=44)$, an equal difference in SF ICTP was found between the above groups - that is, the median concentration of SF ICTP was $14.0 \mu \mathrm{g} / 1$ (range $2.8-42.3 \mu \mathrm{g} / 1$ ) for the $25 \mathrm{RA}$ patients with stable disease and $18.3 \mu \mathrm{g} / 1$ (range $7.1-64.6 \mu \mathrm{g} / \mathrm{l}$ ) for the $19 \mathrm{sub}$ jects whose disease was deteriorating, though the difference did not reach statistical significance $(p=0.063)$. Instead, both the median levels of SF total leucocytes $(p=0.012)$ and polymorphonuclear leucocytes $(\mathrm{p}=0.018)$ were statistically higher in the patients with a stable grade. A comparison of the diagnostic subgroups showed that the association did not hold in the RA group, but was more

Table 2 Serum and synovial fluid markers of collagen metabolism and synovial fluid leucocytes in patients with stable and deteriorating Larsen's grade of knee joint at 0 and three years'visit

\begin{tabular}{llll}
\hline Variable & $\begin{array}{l}\text { Patients with stable Larsen's } \\
\text { grade median (range) }\end{array}$ & $\begin{array}{l}\text { Patients with deteriorating } \\
\text { Larsen's grade median (range) }\end{array}$ & $\begin{array}{c}p \text { value of } \\
\text { Mann-Whitney test }\end{array}$ \\
\hline S-ICTP $(\mu \mathrm{g} / \mathrm{l})$ & $4.1(1.7-14.8)(\mathrm{n}=33)$ & $5.2(1.1-24.2)(\mathrm{n}=21)$ & 0.456 \\
SF-ICTP $(\mu \mathrm{g} / \mathrm{l})$ & $14.0(2.8-42.3)(\mathrm{n}=33)$ & $17.6(7.1-64.6)(\mathrm{n}=22)$ & $0.035^{\star}$ \\
S-PINP $(\mu \mathrm{g} / \mathrm{l})$ & $41.3(15.0-111.3)(\mathrm{n}=32)$ & $44.2(23.8-90.70)(\mathrm{n}=20)$ & 0.458 \\
SF-PINP $(\mu \mathrm{g} / \mathrm{l})$ & $731.0(118.0-5017.0)(\mathrm{n}=31)$ & $869.5(147.0-2462.0)(\mathrm{n}=20)$ & 0.345 \\
S-PIIINP $(\mu \mathrm{g} / \mathrm{l})$ & $3.9(1.8-7.4)(\mathrm{n}=30)$ & $4.4(2.1-11.7)(\mathrm{n}=20)$ & 0.209 \\
SF-PIIINP $(\mu \mathrm{g} / 1)$ & $1099.0(438.0-4781.0)(\mathrm{n}=31)$ & $1378.0(278.0-3905.0)(\mathrm{n}=21)$ & 0.412 \\
SF leucocytes $\left(10^{9} / 1\right)$ & $11.2(3.6-54.8)(\mathrm{n}=32)$ & $5.2(0.1-18.7)(\mathrm{n}=21)$ & $0.012^{\star}$ \\
SF polymorphonuclear leucocytes $\left(10^{9} / 1\right)$ & $7.1(1.0-45.5)(\mathrm{n}=32)$ & $2.7(0-14.1)(\mathrm{n}=21)$ & $0.018^{\star}$
\end{tabular}

$\mathrm{S}=$ serum, SF = synovial fluid. ICTP, cross linked carboxyterminal telopeptide of type I collagen in serum. PINP, aminoterminal propeptide of type I procollagen. PIINP, aminoterminal propeptide of type III procollagen. ${ }^{\star} \mathrm{p}<0.05$. 
pronounced in the other inflammatory arthropathies - that is, the median was $9.8 \times$ $10^{9} / 1$ for stable disease and $11.0 \times 10^{\%} / 1$ for progessive disease in the RA group, while the corresponding values in the other diagnostic groups were $12.6 \times 10^{9} / 1$ and $2.2 \times 10^{9} / 1$. There was no statistically significant difference for $S$ ICTP, S PIIINP, SF PINP or SF PIIINP between the above groups either in the whole series or in the diagnostic subgroups. The mean SF:S ratio of ICTP was 3.1 (SD 1.8) for the patients with a stable Larsen's grade, and 4.5 (3.3) for the patients with a deteriorating Larsen's grade (NS).

There was no statistical difference between the patients with a stable or deteriorating Larsen's grade with regard to treatment with DMARDs or peroral corticosteroid therapy during the follow up.

During the follow up, 13 (42\%) of the 31 patients whose Larsen's grade remained stable and $15(71 \%)$ of the 21 whose grade deteriorated needed one or more corticosteroid injections (including chemical synovectomy in five cases) $(p=0.036)$; for three patients the follow up data were missing.

\section{Discussion}

Markers of collagen synthesis and degradation measured in serum and SF reflect the grade of synovitis and tissue breakdown in RA. ${ }^{1-5}$ The earlier studies to measure collagen degradation were based on the use of urine samples including assays of the imino acid 4-hydroxyproline, pyridinoline and deoxypyridinoline cross links, and showed controversial results as to the association with radiological progression in hands and feet. ${ }^{18} 19$

In the present series, we used serum radioimmunoassays to measure the synthesis and degradation of type I collagen (PINP and ICTP) and the synthesis of type III collagen (PIIINP) in patients with different forms of inflammatory arthritis. Type I collagen is the most abundant protein species in the human body. Most of it is present in bones, where it accounts for about $90 \%$ of the organic matrix, and it is also the major matrix protein in tendons, ligaments, and soft connective tissues. Type III collagen is the second most abundant collagen type and is found in soft connective tissue.

The only study to compare ICTP with the urinary assays of type I collagen degradation was a cross sectional analysis of five different markers of collagen degradation in RA, where the serum ICTP and urinary pyridinoline (PYD) levels were found to be superior to the other markers in discriminating between the RA and control groups. ${ }^{5}$ PYD cross links arise not only from type I collagen degradation, but also from type II collagen degradation in articular cartilage.

At the beginning of the present follow up, the mean SF concentrations of the collagen derived substances studied were high in our patients, and their concentrations correlated with the grade of destruction in the joint. ${ }^{13}$ During the three year follow up, Larsen's grade deteriorated in $22(40 \%)$ patients. These patients had a significantly higher SF
ICTP level at entry than the ones who had a stable grade. Serum ICTP did not have the same predictive significance, nor did the serum or SF assays for PINP and PIIINP. Serum ICTP reflects the type I collagen metabolism in the whole body, but in our earlier community-based RA series, $26 \%$ of the patients with initially increased serum ICTP values required total joint replacement surgery of at least one joint during a three year follow up, compared with $2 \%$ of the patients with initially normal ones. ${ }^{20}$ However, when estimating the outcome of one particular joint, such as a knee in this study, it seems more logical to measure ICTP from SF than from serum.

Interestingly, the total number of SF leucocytes and the number of polymorphonuclear leucocytes were here higher in the patients with a stable erosive grade than in those with a progressive one $(p=0.012$ and $p=0.018$, respectively). A comparison of the diagnostic subgroups showed that the association did not hold true in the RA group, but was more pronounced in the other inflammatory arthropathies. The non-RA patient group represented different arthritides and included a small number of patients $(n=11)$, which decreases reliability of the finding. However, it is to be noted that a recent study on the relation of synovial biopsy findings to SF analysis in 33 patients with inflammatory arthritis suggested that SF cell counts reflect the activity of acute synovial inflammation but not that of chronic inflammation. ${ }^{21}$

In the present series, baseline SF ICTP correlated positively with Larsen's grade, and those with the highest SF ICTP levels most often deteriorated during the follow up. It should be noted that those with a deteriorating Larsen's grade were more often treated with intra-articular corticosteroids than those with a stable grade $(p<0.05)$. Thus, once the breakdown process has started, it is seldom stopped by the present treatment. The role of local corticosteroids in accelerating joint destruction can only be speculated.

We conclude that SF analysis may help in assessing the disease process of a particular joint in patients with inflammatory arthritis. According to our results a high SF ICTP level seems to reflect accelerated synovial tissue and bone degradation. Instead, our preliminary results indicate that a high SF leucocyte level is not necessarily associated with a poor prognosis. More studies are needed to clarify the question of the relation between the level of SF leucocytes and the development of further joint destruction in patients with inflammatory arthritis.

1 Peel N, Eastell R, Russell G. Markers of bone and collagen breakdown in early inflammatory arthritis. Baillieres Clin Rheumatol 1992;6:351-72.

2 Poole AR. Immunochemical markers of joint inflammation, skeletal damage and repair: where are we now? Ann Rheum Dis 1994;53:3-5.

3 Wollheim FA. New insights into joint damage from analysis of released biochemical markers. Br J Rheumatol 1994;33. $1-4$.

4 Taylor AK, Lueken SA, Libanati C, Baylink B J. Biochemical markers of bone turnover for the clinical assessment of bone metabolism. Rheum Dis Clin N Am 1994;20:589607. 
5 St Clair E, Moak S, Wilkinson W, Sanders L, Lang T, Greenwald R. A cross sectional analysis of 5 differen markers of collagen degradation in rheumatoid arthritis. J Rheumatol 1998;25:1472-9.

6 Saxne T, Wollheim F, Petterson H, Heinegård D. Proteoglycan concentration in synovial fluid: predictor of future cartilage destruction in rheumatoid arthritis? BMJ 1987;295: tilage destr-8.

7 Saxne T, Zunino L, Heinegård D. Increased release of bone sialoprotein into synovial fluid reflects tissue destruction in rheumatoid arthritis. Arthritis Rheum 1995;38:82-90.

8 Månsson $\mathrm{B}$, Geborek $\mathrm{P}$, Saxne $\mathrm{T}$. Cartilage and bone macromolecules in knee joint synovial fluid in rheumatoid arthritis: relation to development of knee or hip joint arthritis: relation to development of knee
destruction. Ann Rheum Dis 1997;56:91-6.

9 Fisher L, McBride O, Termine J, Young M. Human bone sialoprotein: deduced protein sequence and chromosomal localization. J Biol Chem 1990;265:2347-51.

10 Risteli J, Elomaa I, Niemi S, Novamo A, Risteli L. Radioimmunoassay for the pyridinoline cross-linked carboxytermimal telop tide of type I collagen: A new serum marker of bone collagen degradation. Clin Chem 1993;39:635-40.

11 Melkko J, Kauppila S, Risteli L, Haukipuro K, Jukkola A, Risteli J. Immunoassay for the intact aminoterminal propeptide of human type I procollagen (PINP). Clin Chem 1996;42:947-54.

12 Risteli J, Niemi S, Trivedi P, Mäentausta O, Mowat A P, Risteli L. Rapid equilibrium radioimmunoassay for the amino-terminal propeptide of human type III procollagen. Clin Chem 1988;34:715-18.
13 Hakala M, Åman S, Luukkainen R, Risteli L, Kauppi M, Nieminen $\mathrm{P}$, et al. Application of markers of collagen metabolism in serum and synovial fluid for assessment of disease process in patients with rheumatoid arthritis. Ann Rheum Dis 1995;54:886-90.

14 Arnett FC, Edworthy SM, Bloch DA, McShane DJ, Fries JF, Cooper NS, et al. The American Rheumatism Association 1987 revised criteria for the classification of rheumatoid arthritis. Arthritis Rheum 1988;31:315-24.

15 Larsen A, Dale K, Eek M. Radiographic evaluation of rheumatoid arthritis and related conditions by standard reference films. Acta Radiol Diagn 1977;18:481-91.

16 SOLO user's guide. Version 2.0. Los Angeles: BMDP Statistical Software Inc, 1988:1-266.

17 SOLO advanced set. Version 2.0. Los Angeles: BMDP Statistical Software Inc, 1988:1-92.

18 Robins SP, Stewart P, Astbury C, Bird HA. Measurement of the cross-linking compound, pyridinoline, in urine as an index of collagen degradation in joint diseases. Ann Rheum Dis 1986;45:969-73.

19 Seibel MJ, Duncan A, Robins SP. Urinary hydroxypyridinium crosslinks provide indices of cartilage and bone involvement in arthritic diseases. J Rheumatol 1989;16: 964-70.

20 Åman S, Hakala M, Risteli L, Risteli J. Increased type I collagen degradation is associated with a need for total joint (1) Ann Dis 1996;55:147.

21 Luukkainen R, Söderström K-O, Huhtala H. Relationship between synovial fluid cells and grade of inflammation in synovium in patients with arthritis. [Abstract]. Scand J Rheumatol 1999;28:198.

\section{政}

